\title{
The Maunder minimum and the Little Ice Age: an update from recent reconstructions and climate simulations
}

\author{
Mathew J. Owens ${ }^{1, *}$, Mike Lockwood ${ }^{1}$, Ed Hawkins ${ }^{1,5}$, Ilya Usoskin ${ }^{2}$, Gareth S. Jones ${ }^{3}$, \\ Luke Barnard $^{1}$, Andrew Schurer ${ }^{4}$ and John Fasullo ${ }^{6}$ \\ ${ }^{1}$ Department of Meteorology, University of Reading, Reading, Berkshire, UK \\ ${ }^{2}$ ReSoLVE Centre of Excellence and Sodankylä Geophysical Observatory, University of Oulu, Finland \\ ${ }^{3}$ Met Office Hadley Centre, Exeter, UK \\ ${ }^{4}$ School of Geosciences, University of Edinburgh, Edinburgh, UK \\ ${ }^{5}$ National Centre for Atmospheric Science, Department of Meteorology, University of Reading, Reading, Berkshire, UK \\ ${ }^{6}$ National Center for Atmospheric Research, Boulder, Colorado, USA
}

Received 20 April 2017 / Accepted 14 November 2017

\begin{abstract}
The Maunder minimum (MM) was a period of extremely low solar activity from approximately $\mathrm{AD} 1650$ to 1715 . In the solar physics literature, the MM is sometimes associated with a period of cooler global temperatures, referred to as the Little Ice Age (LIA), and thus taken as compelling evidence of a large, direct solar influence on climate. In this study, we bring together existing simulation and observational studies, particularly the most recent solar activity and paleoclimate reconstructions, to examine this relation. Using northern hemisphere surface air temperature reconstructions, the LIA can be most readily defined as an approximately 480 year period spanning AD 1440-1920, although not all of this period was notably cold. While the MM occurred within the much longer LIA period, the timing of the features are not suggestive of causation and should not, in isolation, be used as evidence of significant solar forcing of climate. Climate model simulations suggest multiple factors, particularly volcanic activity, were crucial for causing the cooler temperatures in the northern hemisphere during the LIA. A reduction in total solar irradiance likely contributed to the LIA at a level comparable to changing land use.
\end{abstract}

Keywords: Space climate / total irradiance / climate / sunspot / climate change

\section{Introduction}

Solar magnetic activity, as historically measured by the occurrence of sunspots and aurora, varies with the approximately 11 year Schwabe cycle (Hathaway, 2010). Solar activity reconstructions based on cosmogenic radionuclide data, such as $14 \mathrm{C}, 10 \mathrm{Be}$ and $44 \mathrm{Ti}$, show that Schwabe cycles are modulated by much longer-term variations, resulting in grand maxima and grand minima of activity (Usoskin, 2017). The Maunder minimum (MM), AD 1645-1715 (Eddy, 1976; Usoskin et al., 2015), is the most recent grand minimum and the only one covered by telescopic sunspot observations. It is thus of great interest to solar dynamo, space weather and terrestrial climate studies.

In both the scientific literature and wider discourse, discussion of the MM is sometimes accompanied by mention of the Little Ice Age (LIA), a term used to loosely describe a

*Corresponding author: $\mathrm{m} \cdot \mathrm{j}$. owens@reading.ac.uk period of cooler global temperatures sometime during the 13th to 20th centuries. More broadly, claims are often made about the general correspondence between solar activity and global climate variations on centennial time scales. (We deliberately choose not to provide specific examples here as such papers are often not focussed on a sun-climate link and no climate data is considered; climate implications are merely mentioned in passing, possibly as a means of motivating the general study of long-term solar variability.) Claims of a strong, often causal, correspondence between global climate and solar activity commonly occur in press releases accompanying solar variability studies, often with anecdotal arguments for support (e.g., the occurrence of Frost Fairs on the river Thames at London during the MM). We also note that in some cases the link is deemed so strong that the climate term LIA and the solar term MM are used interchangeably.

This runs counter to the scientific understanding of solarclimate relations, which has already been covered by a number of extensive reviews (Gray et al., 2010; Lockwood, 2010a and references therein). By far the most direct mechanism by 


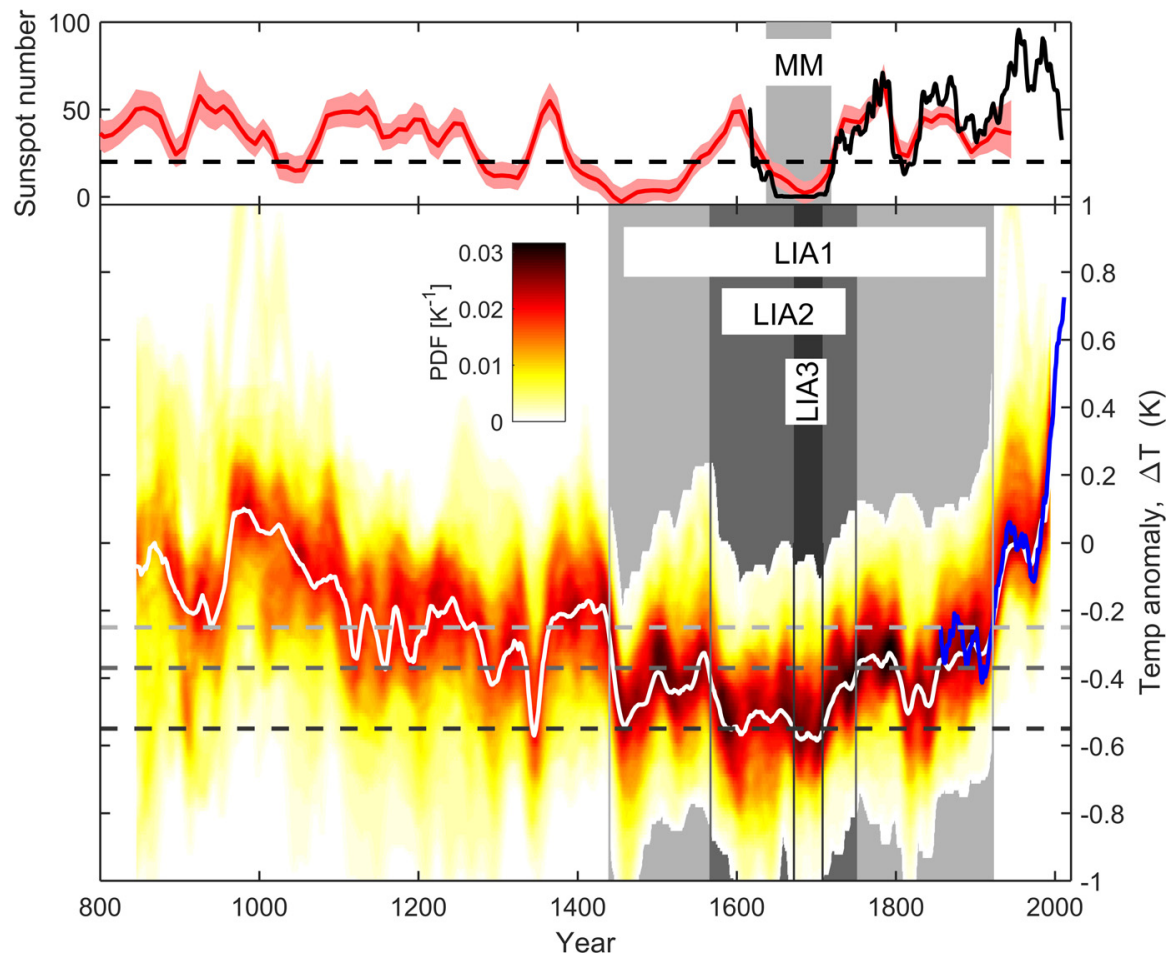

Fig. 1. A comparison of solar activity and northern hemisphere climate from AD 800 to AD 2016. Top: Sunspot number, from direct telescopic observations (black; Lockwood et al., 2014) and reconstructed on the basis of 14C concentrations in tree trunks (red, with pink 1-sigma uncertainty band; Usoskin et al., 2014). Taking a threshold smoothed sunspot number of 20 (dashed black line), the MM spans 1637-1719. Bottom: Northern hemisphere temperature anomaly, $\Delta T$, (relative to the 1961-1990 mean) for paleoclimate reconstructions, as presented in the IPCC fifth assessment report (Masson-Delmotte et al., 2013). Colours, from white through red, show the probability density function (PDF), while the white line shows the PDF maximum value (or mode). The blue line shows $\Delta T$ from the instrumental record (HadCRUT4; Morice et al., 2012). All data have been smoothed using an 11 year running mean. Taking thresholds of $\Delta T=-0.25 \mathrm{~K},-0.37 \mathrm{~K}$ and $-0.55 \mathrm{~K}$ (dashed grey lines) defines LIAs, LIA1, LIA2 and LIA3, respectively.

which the Sun can influence global climate is through changes in total solar irradiance (TSI), which alter the radiative balance of the global climate system. As discussed in Section 3, the effect of TSI variations on global climate is quantified through the use of state-of-the-art climate models and detailed attribution studies and found to be present, but smaller than other effects. The physical reason why the changes in solar forcing are small is the large mass, and hence thermal inertia, of the solar convective zone, which limits TSI changes on decadal-to-millennial timescales to the effects of surface emissivity changes associated with structures in the solar magnetic field (Krivova et al., 2007). But simple correlative arguments, such as the timing of lows in solar activity and global temperature, can still appear to be compelling and are used to infer (implicitly or explicitly) some form of amplification mechanism which is almost never specified.

This study brings together existing simulation and observational results to examine the relation between the MM and LIA. We begin by examining the temporal correlation between solar activity and global temperature variations using the latest reconstructions. The second half of the study examines recent climate model simulations that quantify the relative effects on global climate resulting from variability in solar irradiance, volcanic activity, greenhouse gases and other causes.

\section{Temporal correlations}

Both the global temperature and solar activity records show continual variation on a range of time scales, resulting from a range of different physical processes with a range of possible feedbacks; some well understood, some not. Applying thresholds to these records for the purpose of defining discrete periods for examination in isolation can facilitate easier discussion and comparison. But it is not always relevant to understanding the influence of external forcing (e.g., Meehl et al., 2011; Medhaug et al., 2017). Indeed, the assumed association between the MM and LIA may even partly result from a mixing of solar and climate terminology, with named solar activity periods such as the MM and Spörer minimum (a period of low solar activity from approximately AD 1400 to 1550 ) being used as temporal yard sticks in climate studies, even when causality is not necessarily intended (e.g., Luterbacher, 2001; Camenisch et al., 2016). Nevertheless, this section examines a range of possible threshold-based definitions for LIA and MM. The aim is not to provide a definitive definition, but to play Devil's advocate and assess whether any reasonable definitions exist which produce a temporal correspondence between the LIA and MM. We strongly assert that even if definitions could be found which 


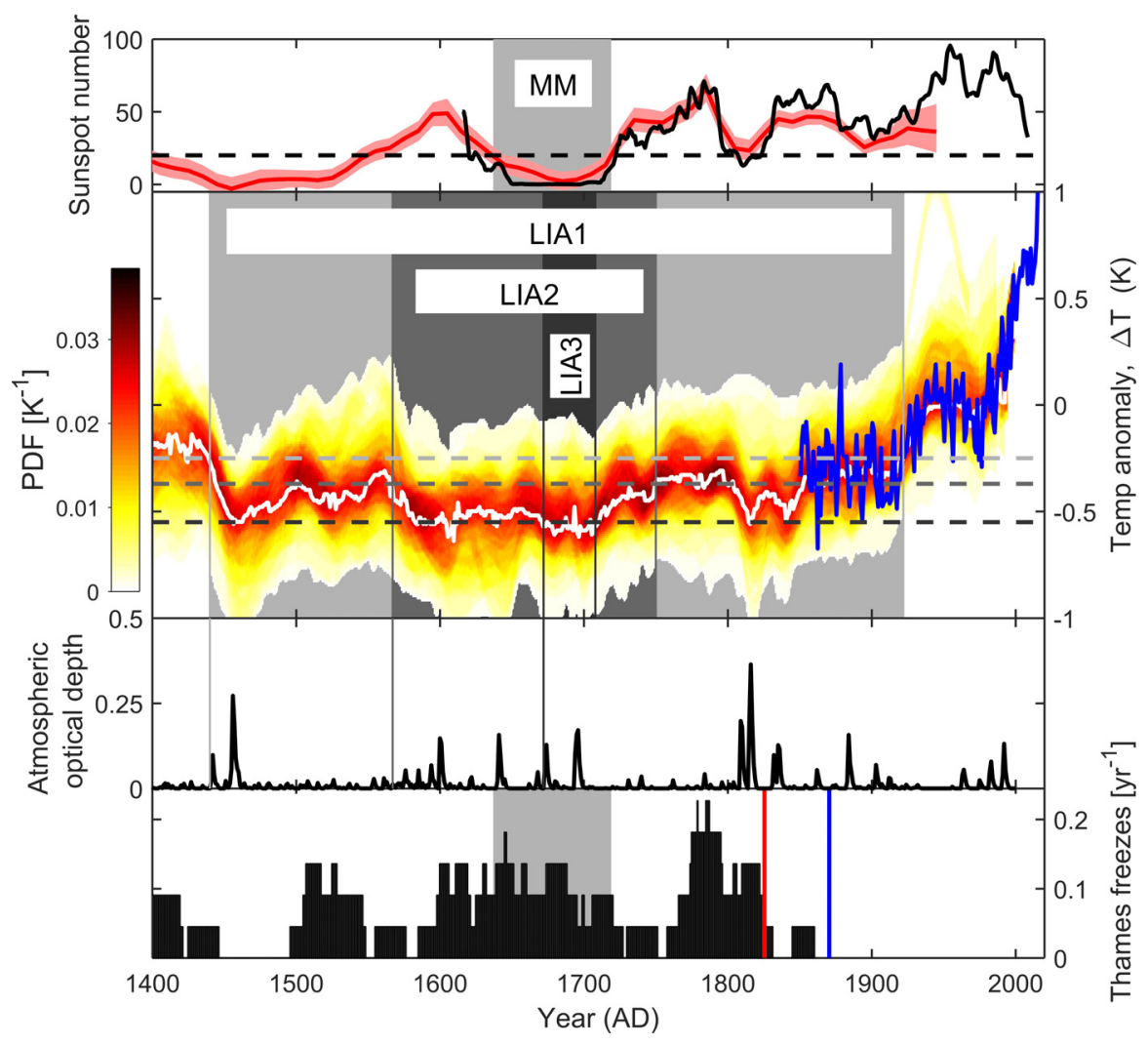

Fig. 2. Climate and solar variations in the period from $\mathrm{AD} 1400$ to $\mathrm{AD} 2016$. The top two panels are the same as Figure 1, but $\Delta T$ data are shown at annual resolution. The third panel shows the global atmospheric optical depth resulting from explosive volcanic activity, as reconstructed from sulphate abundances found in ice core measurements (Crowley and Unterman, 2013). The bottom panel shows the yearly occurrence rate of reports of the Thames freezing in London in a rolling 11 year window. The grey panel shows MM, while the red and blue lines show the dates of demolition of the old London Bridge and the completion of the Thames embankments, respectively.

produce a temporal correlation, it would in no way establish physical causation between the MM and LIA.

We begin by considering solar activity around the MM. The top panel of Figure 1 shows the sunspot record from both telescopic observations (black) and reconstructed from 14C abundance measurements in tree trunks (red). There are ongoing efforts to provide a more accurate long-term calibration of the sunspot record (Clette et al., 2014; Svalgaard and Schatten, 2016; Usoskin et al., 2016), but here we are only concerned with the almost sunspot-free MM period, so the precise activity levels in the 17th century are not of immediate concern and the details of the chosen sunspot reconstruction do not affect the definition of the MM. The black line shows the reconstruction of Lockwood et al. (2014), which extends the international sunspot number (with corrections) through the MM period using the group sunspot record (Hoyt and Schatten, 1998). An 11 year running mean has been applied to minimise the Schwabe cycle variations and display only the long-term trend. The red line shows the sunspot reconstruction (Usoskin et al., 2014) based on 14C abundance measured in living and ancient trees by Reimer et al. (2009), with allowance for the effect of the secular variation in Earth's magnetic field. Due to the effective temporal filtering associated with the carbon sequestration processes, decadal variations are shown. Reconstructions of $14 \mathrm{C}$ after 1900 is complicated by the burning of fossil fuels and use of atomic weapons, which distorts the solar signal in $14 \mathrm{C}$ data. There is, however, good agreement between the direct observations and $14 \mathrm{C}$ reconstructions of sunspot number over most of the period of overlap. In particular, timing and duration of the MM and the early 19th century low (the Dalton minimum, DM) are very similar. Note that prior to 1610 , the solar activity is determined solely by $14 \mathrm{C}$ abundance measurements, which may not be fully independent of climate effects (e.g., Stuiver and Suess, 1966). Thus the MM becomes particularly important for Sunclimate studies. As in Usoskin et al. (2014), we apply a sunspot number threshold of 20 to define a grand minimum, resulting in a MM starting in 1637 and ending in 1719. Applying a different threshold or taking the telescopic record as the standard could change the MM start date by up to a decade, but does not significantly affect the MM end date.

The term LIA was first used to describe glacial advance during the Holocene (Matthes, 1939), the current warm interglacial period, which has persisted for approximately 10000 years. As there is large regional variability in the timings of these glacial advances, defining the LIA in this way gives considerable variation with location. The LIA has since become a general term for more global scales of relatively cooler climate (Masson-Delmotte et al., 2013), though there is still some debate about the statistical significance of this 
temperature depression (Büntgen and Hellmann, 2014; Kelly and Gráda, 2014) and it has been suggested that the term is scientifically misleading due to regional variations in cooling (Landsberg, 1985). Indeed, the LIA is poorly, and often inconsistently, defined. Typical dates range from the LIA starting sometime between AD 1300 and 1450 and ending between AD 1850 and 1900 (Jones and Mann, 2004). Clearly, these start dates are much earlier than that of the MM. Within this approximately 500 year LIA period, however, episodes of intensification (when temperatures are inferred to have dropped further) have also been identified, which could potentially be better synchronised with the timing of the MM.

Here, we use surface air temperature reconstructions to define the LIA start and end times with reduced regional variability. The bottom panel of Figure 1 shows northern hemisphere $(\mathrm{NH})$ surface air temperature instrumental observations and paleoclimate reconstructions. Data are displayed as the temperature anomaly $(\Delta T)$ with respect to the 1961-1990 mean. NH data are used as the early paleoclimate record has much better $\mathrm{NH}$ sampling, thus uncertainties are lower for $\mathrm{NH}$ $\Delta T$ than for global $\Delta T$. All data have been smoothed using an 11 year running mean (annual data are shown in Fig. 2). The blue line shows the HadCRUT4 instrumental record (Morice et al., 2012). The colour contours give the probability distribution function (PDF) of a combination of the 18 separate paleoclimate reconstructions (Masson-Delmotte et al., 2013), as presented in the International Panel on Climate Change (IPCC) 5th Assessment Report (AR5). These reconstructions are based on a wide range of temperature proxies and historical records, not all of which individually cover the whole NH nor the whole year (i.e., some are seasonal). The PDF incorporates both the individual reconstruction uncertainties and the agreement between different reconstructions. The white line shows the PDF maximum. The agreement between the instrumental record and the reconstructions during the period of overlap is very good.

Over the AD 800-2016 period there are number of notable trends in $\Delta T$. From approximately AD 900 to 1100 is a period of enhanced $\Delta T$, in the past often referred to as the medieval warm period, but now more commonly called the medieval climate anomaly (Vaquero and Trigo, 2012; Masson-Delmotte et al., 2013). From AD 1000 to 1700 there is a general downward trend in $\Delta T$ from approximately 0 to $-0.6 \mathrm{~K}$. This cooling is not steady, but appears to proceed through a number of almost step-wise decreases, discussed further below. From AD 1700 onwards there is a general upward trend in $\Delta T$, though the gradient and monotonic nature of the warming increases significantly in the twentieth century, primarily due to atmospheric greenhouse gases from the burning of fossil fuels. Note, however, that regional variations can deviate substantially from this hemispherically-averaged picture (PAGES 2k Consortium, 2013; Abram et al., 2016).

Figure 2 shows the period AD 1400 to 2016. The second panel shows the same $\Delta T$ data as Figure 1, but for raw data (i.e., no 11 year smoothing). Using varying $\Delta T$ thresholds to define the LIA effectively focuses on the two most dramatic and persistent temperature declines, around $\mathrm{AD} 1440$ and $\mathrm{AD}$ 1570, when $\Delta T$ drops within a few decades from around $-0.2 \mathrm{~K}$ to $-0.55 \mathrm{~K}$ and from $-0.35 \mathrm{~K}$ to $-0.55 \mathrm{~K}$, respectively. In order to select the period of coolest temperatures, we define the first candidate for the LIA1 using a $\Delta T$ threshold of $-0.25 \mathrm{~K}$, resulting in LIA1 spanning AD 1440 to 1922, shown as the lightest grey shading in
Figure 2. In order to select the start of the large and persistent temperature decline in the middle of the 16th century, LIA2 is defined using a $\Delta T$ threshold of $-0.37 \mathrm{~K}$, resulting in LIA2 spanning AD 1567 to 1750 , shown by the medium grey shading in Figure 2. Clearly, both these intervals start well before the MM. LIA2 begins during a period of rising solar activity, which peaked around AD 1600 .

Looking only at the most probable value of $\Delta T$ and not the full distribution of temperature reconstructions, however, the very lowest $\Delta T$ is during the $\mathrm{MM}$. Thus, adopting again the role of Devil's Advocate, we define LIA3 using a $\Delta T$ threshold of $-0.55 \mathrm{~K}$, resulting in the period 1672 to 1708 . Appendix A, however, demonstrates that when the full $\triangle T$ PDF is considered, the temperature in LIA3 is not statistically distinct from the previous 85 years. Furthermore, LIA3 still begins nearly 40 years after the start of the MM and ends before the solar activity rises, implying that other factors are involved, even allowing for a delay in the response of the atmosphere to solar forcing.

The third panel of Figure 2 shows the northern hemisphere volcanic aerosol optical depth (AOD) reconstructed from sulphate concentrations in polar ice cores (Crowley and Unterman, 2013). In contrast to the relatively poor temporal correspondence between solar activity and northern hemisphere temperature, there is clear correlation between AOD and some of the downward steps in $\Delta T$. In particular, the start of LIA1 near AD 1440 is associated with a large volcanic eruption, while the LIA2 period is characterised by a general increase in smaller-scale volcanic activity. These periods of abrupt cooling are possibly sustained by sea-ice and ocean feedbacks (Miller et al., 2012). The post-LIA2 warming is interrupted by the cooling periods in the early and mid-19th century, which are similarly associated with intense volcanic activity (though we note these cooling periods are sometimes also attributed to the Dalton minimum in solar activity). Of course, not all of the temperature variation can be explained by volcanic activity, nor should it be expected to.

The Maunder minimum is often also anecdotally associated with an increased occurrence of Frost Fairs on the Thames in London, which is then taken as evidence of a colder climate at the time. As pointed out by Jones (2008), there are two major issues with this line of argument. Firstly, the freezing of the Thames is a very poor indicator of even regional climate on time scales much longer than a few weeks. While decadal average temperatures were lower during the LIA, there was nevertheless still a mixture of hot/cold summers and winters, close to present variability (e.g., Overland and Wood, 2003). Indeed the Central England Temperature record (Manley, 1974) during the LIA shows some of the coldest winters being followed the very next year by some of the warmest (Jones, 2008; Lockwood et al., 2011). In addition, the freezing of the Thames at London is dependent on a number of non-climate factors, such as flow speed, tides and brackishness: it is not climate effects but the removal of the old London Bridge, which had many narrow arches and elements that essentially acted as a weir, and the improved river flow from the embankment work which have primarily led to a reduction in occurrence of the Thames freezing at London since the early 19th century. A more complete discussion of Frost Fairs and Thames freezing events is provided by Lockwood et al. (2017). The second issue is that 
even if such data could be used as an indicator of climate, Thames freezing events at London were not enhanced in MM. The bottom panel of Figure 2 shows the annual occurrence rate of all known historical reports of Frost Fairs or instances of the Thames freezing in London in an 11 year running window (see Lockwood et al., 2017). The freezing occurrence rates in the periods of high solar activities before and after the MM are as high as during the MM and the peak occurrence is roughly 70 years after the end of the MM.

Thus while simple correlative arguments should not be used to establish causation, the timings of MM and the LIA (or Thames Frost Fairs) do not actually show close associations.

\section{Physically-based climate modelling}

Possibly the only way to directly quantify the role of different factors causing climate variations is to use climate simulators. These computer models vary from simple representations of the energy flow through the atmosphere (sometimes including the stratosphere in addition to the troposphere), oceans and into space, to much more complex models which solve physical and chemical equations to represent the key components of the climate system in threedimensions. Depending on the sophistication of the model, the atmosphere, ocean, sea ice, land ice, soils, topography, land type, etc., can all be represented. These models can be used to simulate the climate response to many different factors, for example, changes in atmospheric composition, different levels of solar and volcanic activity, and changes in land use type or Earth's orbit around the sun. However, they are necessarily simplified versions of the true climate system and their simulated response is dependent on our knowledge of past variations in the key factors, such as solar activity.

Previous studies have shown that the general evolution of northern hemisphere temperatures can be described by model simulations driven by changes in human and natural factors (e.g., Fig. 5.8 in Masson-Delmotte et al., 2013), despite uncertainties in how climate is simulated across different models and in uncertainties in how climate forcing factors changed in the past. Analysis approaches that compare the patterns of change due to different factors with those observed and reconstructed support the important role of changes in greenhouse gas concentrations and explosive volcanic activity, but suggest that solar activity played a relatively minor role (Schurer et al., 2014).

Figure 3 shows simulated changes in northern hemisphere average temperatures in the most comprehensive set of simulations of the climate of the past millennium to date. These simulations are part of the CESM Last Millennium Ensemble (Otto-Bliesner et al., 2016) and are estimates of how temperatures would have varied given prescribed changes in six sets of factors (or radiative forcings), namely: greenhouse gases (GHGs), other anthropogenic (human) causes (mainly due to sulphate particulates, termed aerosols, and changes in stratospheric ozone induced by CFCs), total solar irradiance (TSI), explosive volcanic activity, orbital changes and humandriven land-use changes (see Appendix B for more details). These are also combined to produce an estimate of climatic variations including all these factors. There are multiple simulations (an ensemble) in each case which only differ due to

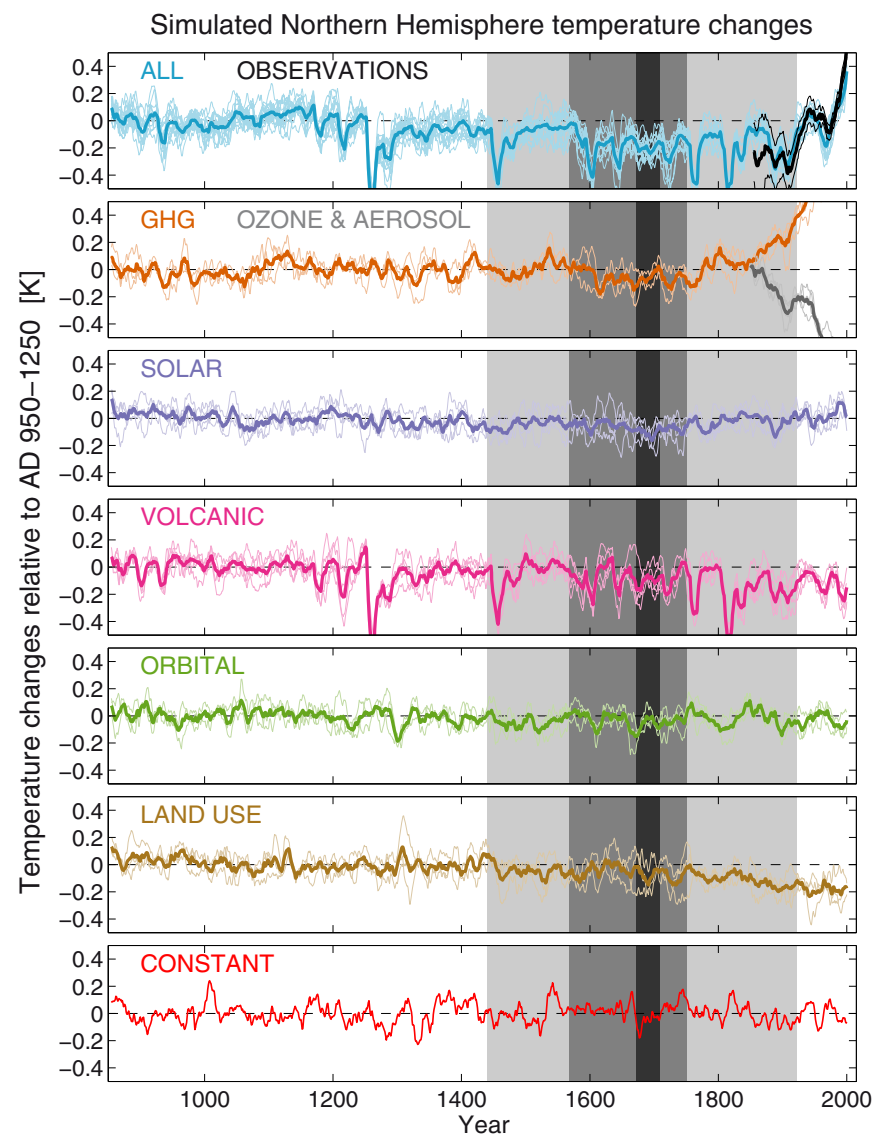

Fig. 3. Simulated northern hemisphere temperature changes, smoothed with an 11 year running mean, relative to the period $\mathrm{AD}$ 950-1250, using the CESM-LME global climate model (data from Otto-Bliesner et al. (2016), see Appendix B for more details of the simulations and data processing). The different panels show simulations with isolated climate factors, while the top panel shows simulations performed with all of the known radiative forcings evolving together. The black line in the top panel shows the observed instrumental northern hemisphere temperature variations with their associated uncertainties (Morice et al., 2012), which match the simulations well. The bottom panel shows a simulation with no changes to the radiative forcings. This quantifies the magnitude of natural internal variability in the simulations in the absence of changes in forcings. Note that the green house gas ensemble mean reaches $1.5 \mathrm{C}$ in 2005 , while ozone/aerosol reaches $-0.85 \mathrm{C}$, and that there are different numbers of ensemble members for each set of factors (see Appendix B). The individual simulations are shown by thin lines and the ensemble mean by the thick lines. Grey shaded regions represent the three LIA Periods, with the darkest interval (LIA3) being the closest in timing to MM.

random internal fluctuations of the climate system, such as El Nino events, that are not driven by the external factors listed above. The thin lines in each panel represent temperature changes in each ensemble member, and the thick lines are the ensemble mean. Note that the changes $(\Delta T)$ are shown relative to AD 950-1250 so as to explore the causes of the cooling from that period to the LIA.

In addition, there is one simulation with no changes in radiative forcings (labelled CONSTANT, bottom row), and 
this is an example of how the climate varies even without any changes to the forcing factors listed above. Note that this simulation has many apparent bumps and wiggles due to random fluctuations in surface temperatures, highlighting that not every observed variation has to be due to a change in external factors. Such internal variations are common in both observations and climate simulations and are often associated with temporary energy exchanges within the climate system, for example additional heat uptake or release from the deeper ocean (Deser et al., 2010).

The low frequency simulated changes in northern hemisphere temperature from $\mathrm{AD} 900$ to 1850 are smaller than inferred from the proxy evidence (Sect. 2). This could indicate an issue with interpreting the proxies, which are indirect measurements of temperature spread sparsely over the hemisphere, especially further back in time. Alternatively, the difference may arise due to errors in the radiative forcings or the simulated response to those forcings.

According to these simulations, changes in land use contribute a slow, but near-continual, cooling of the climate throughout $\mathrm{AD} 900$ to present (although note that the magnitude of this effect is different in other models). This cooling is due to the removal of natural land cover (e.g. forests) which often produces a more reflective surface (higher albedo) that reflects more solar radiation back into space, particularly in snow-covered regions during winter, thus cooling the climate. Changes in the level of dust in the atmosphere likely also play a role. Note that the removal of forests also increases the levels of carbon dioxide in the atmosphere, which warms the climate, but this factor contributes to the GHG component. There is little net effect of changes in Earth's orbit around the Sun over the AD 900 to present interval.

More striking for the LIA periods are the simulated temperature changes due to explosive volcanic activity, which produce sporadic large cooling events, due to the emission of sulphur dioxide into the upper atmosphere, forming particulates that scatter incoming sunlight. Total solar irradiance also plays an important role, with the estimated reduction of incoming shortwave energy producing slightly cooler temperatures during the LIA periods than before or after. Perhaps more surprising is the contribution that GHGs make to the cooling in these periods (Schurer et al., 2013). The reduction of carbon dioxide atmospheric concentrations around 1600 may have both a human and natural cause, perhaps related to vegetation changes from agricultural practices, perhaps as part of a feedback effect with more $\mathrm{CO}_{2}$ being stored in the cooler oceans or expanded ice sheets.

After 1850, human factors play an increasingly dominant role with increasing levels of aerosol particulates (produced by the burning of fossil fuels) in the atmosphere acting to reflect sunlight, and offsetting some of the warming due to increases in GHGs.

We can quantify the role of these different factors by averaging the simulated temperature changes during the LIA periods and the MM (Fig. 4). These panels highlight that for each chosen period there are multiple factors which act together to produce the overall simulated cold temperatures. Particularly important are the volcanic eruptions, which are the largest factor (especially for LIA1), but reduction in total solar irradiance is also contributing to changes in large-scale temperatures (also see Masson-Delmotte et al. (2013) and

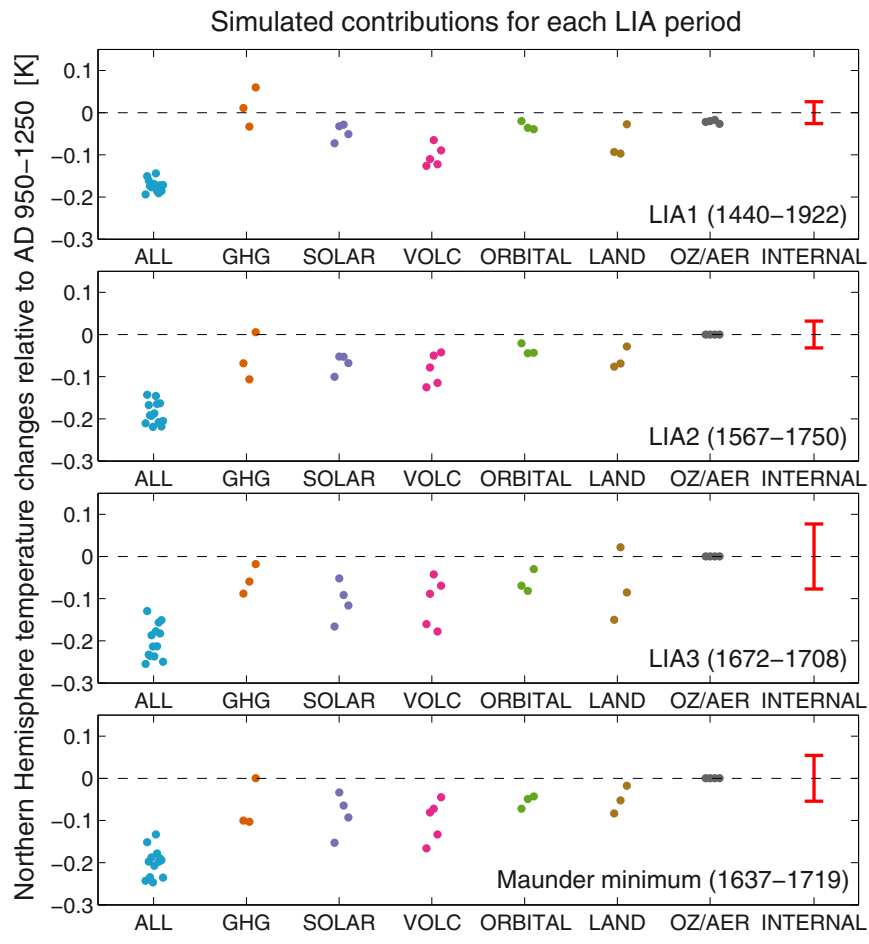

Fig. 4. Simulated northern hemisphere temperature changes, relative to AD 950-1250, using the CESM-LME global climate model (data from Otto-Bliesner et al., 2016). Temperature changes have been averaged over periods of interest for each simulation, representing the contribution of different factors to the overall simulated cooling. The temperature anomalies are different for different ensemble members and the differences between them for each simulation type are due to the internal fluctuations in climate, the typical size of which are indicated by the red bars, which are larger for shorter averaging periods.

Schurer et al. (2014)). At other specific times, different factors are important - for example, the largest factor in cooler simulated temperatures from 1610 to 1640 is a reduction in atmospheric carbon dioxide concentrations.

The red bars in Figure 4 show the expected size of possible variations due to internal climate variability alone, derived from the CONSTANT simulation (see Appendix B). These are approximately the same size as the differences between the ensemble members in each set of simulations. This highlights that the observed cooling could have been partly due to internal variability, but could have also been offset by an internal climate variation of the opposite sign. Precisely disentangling the size of the change due to external forcings and internal variations is challenging.

Interestingly, in the very recent period, the simulations suggest that the observed warming is almost entirely explained by human causes with the combined natural effects of orbital changes, total solar irradiance and volcanic eruptions cancelling out or perhaps even acting to cool the climate (Bindoff et al., 2013).

\section{Discussion}

The Maunder minimum is the most recent grand minimum of solar activity (Usoskin et al., 2015; Usoskin, 2017). In the 
solar and space physics literature it is often assumed the MM is contemporaneous with, and sometimes even directly causative of, the LIA, a cooler period in Europe and/or the northern hemisphere. The present study has brought together the latest solar and climate reconstructions, as well as climate model simulations, to examine this relation. While temporal correlation in reconstructions cannot establish causation, it is still useful to establish whether such a correlation exists as a basis for exploring causation further in models.

Direct telescopic sunspot observations and reconstructions of solar activity based on cosmogenic radionuclides such as $14 \mathrm{C}$ in tree trunks both show the MM spanned approximately from AD 1645 to 1715 . We have used temperature thresholds applied to the northern hemisphere paleoclimate reconstructions to define the timing of the LIA. There is a relatively abrupt LIA onset around AD 1440, with gradual warming possibly extending as late as the 1920s. Within this longer envelope period (referred to as LIA1 in this study) there are a number of intensifications of cooler temperatures. The most prominent, LIA2, began fairly gradually around AD 1570 and ends around AD 1750. The LIA1 temperature rise is then further interrupted by two short-lived ( $10-30$ year) drops in northern hemispheric temperature in the early and mid-19th century. At its deepest points, the LIA in northern hemisphere gave average temperatures that were about $0.5 \mathrm{~K}$ cooler than the 1961-1990 average. Regional climate records can deviate significantly from this picture, and display far larger variability. While the MM does fall within the LIA2 intensification period, it clearly cannot be said to have triggered it, as LIA 2 begins approximately 80 years before the MM. Indeed, there is no quantitative definition for a LIA which can give a period of overlap with the MM that might be taken as suggestive of direct causation.

Looking more broadly at the temporal correlations between the solar and climate reconstructions, it is worth noting that the extended LIA1 interval does contain both the Spörer (approximately AD 1390 to 1540) and the Maunder minima, two of the most intense grand solar minima in the 9,400 year record. But a credible argument for simple cause and effect is not possible for four reasons: (1) the LIA1 period begins very abruptly around 50 years after the start of the Spörer minimum; (2) the LIA2 intensification period begins in the period of relatively high solar activity between the Spörer and Maunder minima; (3) the onset of MM appears to have no further effect on temperature (whereas persistent cooling would be an expected result of a prolonged minimum); and (4) the final mid-19th century intensification occurs during a period of relatively high solar activity. Conversely, many of the LIA features discussed above can be readily associated with volcanic activity, though again there is not a one-to-one correlation. Examining the surviving reports of Frost Fairs and Thames freezings at London, there is also no evidence of increased occurrence during the MM.

The latest climate model simulation results are largely in agreement with these simple correlative conclusions. In the 20th century, global temperature variations have been dominated by anthropogenic effects. But the simulations suggest a more complex story before the recent dominance of the GHG forcing: many different factors probably caused the cooler temperatures during the LIA periods and no one factor alone is responsible. Overall, it is likely that the effect of volcanic eruptions was the largest influence, followed by the drop in solar activity and changes in land use. Internal climate variability could also have played a role, especially on smaller temporal and spatial scales where the magnitude of random fluctuations is larger. We again highlight that these simulations, from one model, rely on particular reconstructions of the various factors involved and that using different reconstructions or different climate models may alter the quantitative attribution. Of particular note for this study, larger variations in TSI between the MM and modern era have been proposed (Shapiro et al., 2011), which would obviously increase the amplitude of the solar forcing. However, all longterm TSI reconstructions are still ultimately based on either the sunspot or cosmogenic radionuclide records, so the timing and relative amplitudes are unchanged. Model-free, multi-regression studies suggest larger TSI variations would be inconsistent with the observed temperature variation (Lockwood, 2008). Similarly, increasing the magnitude of solar forcing in climate models results in temperature variations which are inconsistent with the proxy reconstructions (Feulner, 2011; Schurer et al., 2014). Furthermore, improved observations and increased understanding of the physical processes which affect TSI have generally led to decrease in the estimated TSI variation between the MM and present (e.g., Lean, 2000; Krivova et al., 2007; Lean and Rind, 2009; Vieira et al., 2011). Thus according to these and many other similar simulations, any conclusion of a simple causal link between only solar activity and colder temperatures at these times is not justified.

That is not to say that there are no significant climate implications of solar activity, particularly at the regional level or when individual seasons are considered. We note there is considerable observational and modelling evidence for an increased frequency of relatively cold European winters during low solar activity (Lockwood, 2010b; Lockwood et al., 2011; Ineson et al., 2015; Maycock et al., 2015). It is important to note that such regional effects primarily involve a redistribution of heat rather than a net change. Furthermore, the small amplitudes involved mean the link can only be determined statistically and it is not possible to attribute specific events.

Acknowledgements. MJO, ML and LB are part-funded by Science and technology facilities council (STFC) grant number ST/M000885/1. MJO acknowledges support from the Leverhulme Trust through a Philip Leverhulme Prize. EH is supported by the National Centre for Atmospheric Science. GSJ was supported by the Joint UK BEIS/Defra Met Office Hadley Centre Climate Programme (GA01101). JF's participation in this work was supported through NSF Award ID AGS 1243107. IU acknowledges support by the Academy of Finland to the ReSoLVE Center of Excellence (project No. 272157). AS is funded by ERC, by advanced grant TITAN (EC-320691), and NERC, through the Belmont forum, grant PacMedy (NE/P006752/1). The editor thanks three anonymous referees for their assistance in evaluating this paper.

\section{References}

Abram NJ, McGregor HV, Tierney JE, Evans MN, McKay NP, Kaufman DS, and PAGES 2k Consortium. 2016. Early onset of 
industrial-era warming across the oceans and continents. Nature 536: 411-418. DOI:10.1038/nature 19082.

Berger A. 1978. Long-term variations of caloric insolation resulting from the Earth's orbital elements, Quat Res 9: 139-167. DOI:10.1016/0033-5894(78)90064-9.

Bindoff NL et al. 2013. Detection and attribution of climate change: from global to regional. In Climate Change 2013: The Physical Science Basis. Contribution of Working Group I to the Fifth Assessment Report of the In tergovernmental Panel on Climate Change, Stocker TF, Qin D, Plattner G-K, Tignor M, Allen SK, Boschung J, Nauels A, Xia Y, Bex V, Midgley PM, eds., Cambridge, United Kingdom: Cambridge University Press, pp. 867-952. DOI:10.1017/CBO9781107415324.022.

Büntgen U, Hellmann L. 2014. The Little Ice Age in scientific perspective: cold spells and caveats. J Interdiscipl Hist 44: 353368. DOI:10.1162/JINH a 00575.

Camenisch C, Keller KM, Salvisberg M, Amann B, Bauch M, Blumer S, Brázdil R, Brönnimann S, Büntgen U, Campbell BM. 2016. The 1430s: a cold period of extraordinary internal climate variability during the early Spörer Minimum with social and economic impacts in north-western and central Europe. Clim Past 12: 2107. DOI:10.5194/cp-12-2107-2016.

Clette F, Svalgaard L, Vaquero JM, Cliver EW. 2014. Revisiting the Sunspot Number. Sp Sci Rev 186: 35-103. DOI:10.1007/ s11214-014-0074-2.

Crowley TJ, Unterman M. 2013. Technical details concerning development of a $1200 \mathrm{yr}$ proxy index for global volcanism. Earth Syst Sci Data 5: 187-197. DOI:10.5194/essd-5-187-2013.

Deser C, Alexander MA, Xie S-P, Phillips AS. 2010. Sea surface temperature variability: patterns and mechanisms. Annu Rev Mar Sci 2: 115-143. DOI:10.1146/annurev-marine-120408-151453.

Eddy JA. 1976. The Maunder minimum. Science 192: 1189-1202. DOI:10.1126/science.192.4245.1189.

Feulner G. 2011. Are the most recent estimates for maunder minimum solar irradiance in agreement with temperature reconstructions? Geophys Res Lett 38. DOI:10.1029/2011GL048529.

Gao C, Robock A, Ammann C. 2008. Volcanic forcing of climate over the past 1500 years: An improved ice core-based index for climate models. J Geophys Res: Atmos 113. DOI:10.1029/2008JD010239.

Gray LJ, Beer J, Geller M, Haigh JD, Lockwood M, Matthes K, Cubasch U, Fleitmann D, Harrison G, Hood L. 2010. Solar influences on climate. Rev Geophys 48.

Hathaway DH. 2010. The solar cycle. Liv Rev Sol Phys 7: 1. DOI:10.1007/lrsp-2015-4.

Hoyt DV, Schatten KH. 1998. Group sunspot numbers: a new solar activity reconstruction. Sol Phys 181: 491-512. DOI:10.1023/ A:1005007527816.

Hurtt GC et al. 2011. Harmonization of land-use scenarios for the period 1500-2100: 600 years of global gridded annual land-use transitions, wood harvest, and resulting secondary lands. Clim Chang 109: 117. DOI:10.1007/s10584-011-0153-2.

Ineson S, Maycock AC, Gray LJ, Scaife AA, Dunstone NJ, Harder JW, Knight JR, Lockwood M, Manners JC, Wood RA. 2015. Regional climate impacts of a possible future grand solar minimum. Nat Commun 6: 7535. DOI:10.1038/ncomms 8535.

Jones P. 2008. Historical climatology - a state of the art review. Weather 63: 181-186. DOI:10.1002/wea.245.

Jones PD, Mann ME. 2004. Climate over past millennia. Rev Geophys 42: RG2002. DOI:10.1029/2003RG000143.

Kay J, Deser C, Phillips A, Mai A, Hannay C, Strand G, Arblaster J, Bates S, Danabasoglu G, Edwards J. 2015. The community earth system model (CESM) large ensemble project: a community resource for studying climate change in the presence of internal climate variability. Bull Am Meteorol Soc 96: 1333-1349. DOI:10.1175/BAMS-D-13-00255.1.

Kelly M, Gráda CÓ. 2014. The waning of the Little Ice Age: climate change in early modern Europe. J Interdiscip Hist 44: 301-325. DOI:10.1162/JINH_a_00573.

Krivova NA, Balmaceda L, Solanki SK. 2007. Reconstruction of solar total irradiance since 1700 from the surface magnetic flux. Astron Astrophys 467: 335-346. DOI:10.1051/ 0004-6361:20066725.

Lamarque JF et al. 2010. Historical (1850-2000) gridded anthropogenic and biomass burning emissions of reactive gases and aerosols: methodology and application. Atmos Chem Phys 10: 7017-7039. DOI:10.5194/acp-10-7017-2010.

Landsberg HE. 1985. Historic weather data and early meteorological observations. In Palaeoclimatic Analysis and Modelling. ed. Hecht AD. New York: Wiley and Sons, pp.27-70.

Lean J. 2000. Evolution of the Sun's spectral irradiance since the Maunder minimum. Geophys Res Lett 27: 2425-2428. DOI:10.1029/2000GL000043.

Lean JL, Rind DH. 2009. How will Earth's surface temperature change in future decades? Geophys Res Lett 36. DOI:10.1029/ 2009 GL038932.

Lockwood M. 2008. Recent changes in solar outputs and the global mean surface temperature. III. Analysis of contributions to global mean air surface temperature rise. In Proceedings of the Royal Society A: Mathematical, Physical and Engineering Science, 464, pp. 1387-1404. DOI:10.1098/rspa.2007.0348.

Lockwood M. 2010a. Solar change and climate: an update in the light of the current exceptional solar minimum. Proc $R$ Soc $A$ 466: 303-329. DOI:10.1098/rspa.2009.0519.

Lockwood M. 2010b. Solar influence on global and regional climates. Surv Geophys 33: 503-534. DOI:10.1007/s10712-012-9181-3.

Lockwood M, Harrison RG, Owens MJ, Barnard L, Woollings T, Steinhilber. F. 2011. The solar influence on the probability of relatively cold UK winters in the future. Environ Res Lett 6: 034004. DOI:10.1088/1748-9326/6/3/034004.

Lockwood M, Owens MJ, Barnard L. 2014. Centennial variations in sunspot number, open solar flux, and streamer belt width: 1 . Correction of the sunspot number record since 1874. J Geophys Res 119: 5172-5182. DOI:10.1002/2014JA019970.

Lockwood M, Owens MJ, Hawkins E, Jones G, Usoskin I. 2017. The solar Maunder minimum, the Little Ice Age and the freezing of the river Thames at London. Astron Geophys 58: 2.17-12.23. DOI:10.1093/astrogeo/atx057.

Luterbacher J. 2001. The late Maunder minimum (1675-1715) climax of the Little Ice Age in Europe. In History and Climate, edited, Berlin, German: Springer, pp. 29-54.

Manley G. 1974. Central England temperatures: monthly means 1659 to 1973. Q J Royal Meteorol Soc 100: 389-405. DOI:10.1002/ qj.49710042511.

Masson-Delmotte $\mathrm{V}$ et al. 2013. Information from paleoclimate archives. In Climate Change 2013: The Physical Science Basis. Contribution of Working Group I to the Fifth Assessment Report of the Intergovernmental Panel on Climate Change, Stocker TF, Qin D, Plattner G-K, Tignor M, Allen SK, Doschung J, Nauels A, Xia Y, Bex V, Midgley PM, eds. Cambridge: Cambridge University Press, pp. 383-464. DOI:10.1017/CBO9781107415324.013.

Matthes FE. 1939. Report of Committee on Glaciers, April 1939. Trans Am Geophys Union 20: 518-523. DOI:10.1029/ TR020i004p00518.

Maycock AC, Ineson S, Gray LJ, Scaife AA, Anstey JA, Lockwood M, Butchart N, Hardiman SC, Mitchell DM, Osprey SM. 2015. Possible impacts of a future grand solar minimum on climate: 
stratospheric and global circulation changes. J Geophys Res Atmos 120: 9043-9058. DOI: $10.1002 / 2014 J D 022022$.

Medhaug I, Stolpe MB, Fischer EM, Knutti R. 2017. Reconciling controversies about the global warming hiatus. Nature 545: 41-47. DOI:10.1038/nature22315.

Meehl GA, Arblaster JM, Fasullo JT, Hu A, Trenberth KE. 2011. Model-based evidence of deep-ocean heat uptake during surfacetemperature hiatus periods. Nat Clim Change 1: 360-364. DOI:10.1038/nclimate1229.

Miller GH et al. 2012. Abrupt onset of the Little Ice Age triggered by volcanism and sustained by sea-ice/ocean feedbacks.Geophys Res Lett 39. DOI:10.1029/2011GL050168.

Morice CP, Kennedy JJ, Rayner NA, Jones PD. 2012. Quantifying uncertainties in global and regional temperature change using an ensemble of observational estimates: The HadCRUT4 data set, $J$ Geophys Res: Atmos 117. DOI:10.1029/2011JD017187.

Otto-Bliesner BL, Brady EC, Fasullo J, Jahn A, Landrum L, Stevenson S, Rosenbloom N, Mai A, Strand G. 2016. Climate variability and change since $850 \mathrm{CE}$ : an ensemble approach with the community earth system model. Bull Am Meteorol Soc 97: 735754. DOI:10.1175/BAMS-D-14-00233.1.

Overland, JE, Wood K. 2003. Accounts from 19th-century Canadian Arctic explorers' logs reflect present climate conditions. Eos Trans Am Geophys Union 84: 410-412. DOI:10.1029/2003EO400003.

PAGES 2k Consortium. 2013. Continental-scale temperature variability during the past two millennia. Nat Geosci 6: 339-346. DOI:10.1038/ngeo1797.

Pongratz J, Reick C, Raddatz T, Claussen M. 2008. A reconstruction of global agricultural areas and land cover for the last millennium. Glob Biogeochem Cycles 22. DOI:10.1029/2007GB003153.

Reimer PJ, Baillie MG, Bard E, Bayliss A, Beck JW, Blackwell PG, Ramsey CB, Buck CE, Burr GS, Edwards RL. 2009. IntCal09 and Marine09 radiocarbon age calibration curves, 0-50 000 years cal BP. Radiocarbon 51: 1111-1150. DOI:10.1017/ S0033822200034202.

Schmidt GA et al. 2011. Climate forcing reconstructions for use in PMIP simulations of the last millennium (v1.0). Geosci Model Dev 4: 33-45. DOI:10.5194/gmd-4-33-2011.

Schurer AP, Hegerl GC, Mann ME, Tett SF, Phipps SJ. 2013. Separating forced from chaotic climate variability over the past millennium. $J$ Clim 26: 6954-6973. DOI:10.1175/JCLI-D-12-00826.1.
Schurer AP, Tett SFB, Hegerl GC. 2014. Small influence of solar variability on climate over the past millennium. Nat Geosci 7: 104 108. DOI:10.1038/ngeo2040.

Shapiro A, Schmutz W, Rozanov E, Schoell M, Haberreiter M, Shapiro A, Nyeki S. 2011. A new approach to the long-term reconstruction of the solar irradiance leads to large historical solar forcing. Astron Astrophys 529: A67. DOI:10.1051/0004-6361/ 201016173.

Stuiver M, Suess HE. 1966. On the relationship between radiocarbon dates and true sample ages. Radiocarbon 8: 534-540. DOI:10.1017/S0033822200000345.

Svalgaard L, Schatten KH. 2016. Reconstruction of the sunspot group number: the backbone method. Sol Phys 1-32. DOI:10.1007/ s11207-015-0815-8.

Tett SFB, Betts R, Crowley TJ, Gregory J, Johns TC, Jones A, Osborn TJ, Öström E, Roberts DL, Woodage MJ. 2007. The impact of natural and anthropogenic forcings on climate and hydrology since 1550. Clim Dyn 28: 3-34. DOI:10.1007/s00382-006-0165-1.

Usoskin IG. 2017. A history of solar activity over millennia. Liv Rev Sol Phys 14. DOI:10.1007/s41116-017-0006-9.

Usoskin I et al. 2015. The Maunder minimum (1645-1715) was indeed a grand minimum: a reassessment of multiple datasets. Astron Astrophys 581: A95. DOI: 10.1051/0004-6361/201526652.

Usoskin I, Kovaltsov G, Lockwood M, Mursula K, Owens M, Solanki S. 2016. A new calibrated sunspot group series since 1749: statistics of active day fractions. Sol Phys 291: 2685-2708. DOI:10.1007/s11207-015-0838-1.

Usoskin IG, Hulot G, Gallet Y, Roth R, Licht A, Joos F, Kovaltsov GA, Thébault E, Khokhlov A. 2014. Evidence for distinct modes of solar activity. Astron Astrophys 562. DOI:10.1051/0004-6361/ 201423391.

Vaquero JM, Trigo RM. 2012. A note on solar cycle length during the medieval climate anomaly. Sol Phys 279: 289-294. DOI:10.1007/ s11207-012-9964-1.

Vieira LEA, Solanki SK, Krivova NA, Usoskin I. 2011. Evolution of the solar irradiance during the holocene. Astron Astrophys 531: A6. DOI:10.1051/0004-6361/201015843.

Cite this article as: Owens MJ, Lockwood M, Hawkins E, Usoskin I, Jones GS, Barnard L, Schurer A, Fasullo J. 2017. The Maunder minimum and the Little Ice Age: an update from recent reconstructions and climate simulations. J. Space Weather Space Clim. 7: A33 


\section{Appendix A: The significance of the LIA3 period}

The LIA3 period, 1672 to 1708 , is defined using a $\Delta T$ threshold of $-0.55 \mathrm{~K}$. The most probable value of $\Delta T$ in LIA 3 is only around $0.05 \mathrm{~K}$ lower than the preceding 85 years (i.e., back to the start of LIA2), which raises the question of whether such a difference is statistically meaningful within the uncertainty of the reconstructions. The top panels in Figure 5 show the paleoclimate $\Delta T$ PDFs centred on the 3 proposed LIA periods. The blue lines show the duration of the LIA, while the black line shows the 85 year interval prior to the start of the LIA ( 85 years is chosen as the longest period which avoids overlap with other LIA start dates). The bottom panels show the PDFs over the prior and LIA periods, generated by summing the individual annual PDFs (thus these PDFs capture the uncertainty in $\Delta T$ as well as the variability within the interval and each year is given equal weighting). The dashed vertical lines show the means of the PDFs, though caution should be taken as the distributions are not normal. For $\Delta T$ during LIA1 and LIA2, the PDFs are distinct for prior to and within the LIA. For LIA3, the period within the LIA is not distinct from the previous 85 years within the uncertainties of the data. When the data uncertainties are incorporated, the mean $\Delta T$ within LIA3 is slightly higher than during the preceding 85 years, in contrast to the mode. Thus for any reasonable definition of the LIA, the temperature decrease occurred at least 70 years before the onset of the MM.

\section{Appendix B: Details of the CESM-LME climate simulations}

The full details of the CESM-LME simulations are given in Otto-Bliesner et al. (2016), but here we give a short summary of the assumed changes in known radiative forcings.
Greenhouse gas concentrations are adopted from measurements of $\mathrm{CO}_{2}, \mathrm{CH}_{4}$ and $\mathrm{N}_{2} \mathrm{O}$ in Antarctic ice cores (Schmidt et al., 2011). The volcanic activity follows the Gao et al. (2008) reconstruction, also derived from ice core records. The total solar irradiance is varied according to Vieira et al. (2011) which also includes spectral variations (Schmidt et al., 2011). The parameters of Earth's orbit around the sun, and the resulting changes in insolation, follow Berger (1978). Changes in land use type and cover follow the estimates of Pongratz et al. (2008) and Hurtt et al. (2011), which detail changes in crop and pasture area. The changes in stratospheric ozone and aerosols since 1850 follow those assumed in Kay et al. (2015) and Lamarque et al. (2010), respectively.

There are different numbers of simulations for each forcing combination: all forcings (13), GHGs only (3), other ozoneaerosol only (4, from 1850 onwards), solar only (4), volcanic only (5), orbital only (3), land-use changes only (3) and constant 850 forcings (1).

The control simulation with constant forcings is used to diagnose the drift in simulated climate due to small energy imbalances in the climate model (Otto-Bliesner et al., 2016). A linear trend is fitted over the period $850-2005$ in the CONSTANT simulation, and this trend $(-0.002 \mathrm{~K} /$ century $)$ is removed from each individual simulation before analysis. This is a standard procedure to ensure that model drift does not contaminate the attribution results (Tett et al., 2007).

The estimates of internal variability (red bars in Fig. 4) are derived by examining variances in different overlapping segments of the CONSTANT simulation of the same length as the reference period and the particular period in question. These are added in quadrature to produce estimates for the expected variability contribution to the range of ensemble members.
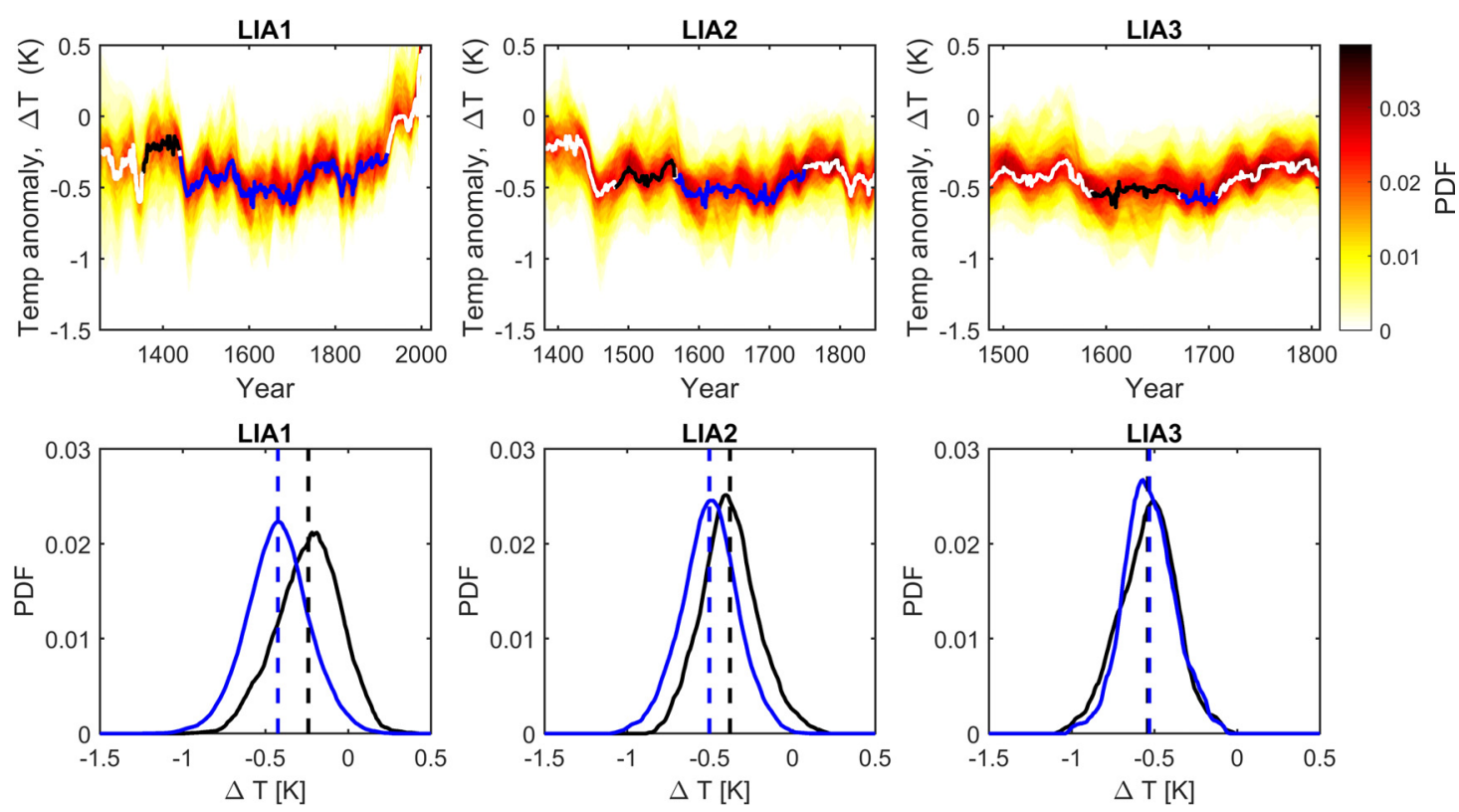

Fig. 5. Top: Time series of the paleoclimate $\Delta T$ PDFs centred on the three possible LIA dates. Blue lines show the duration of the LIAs, while black lines shows the 85 year intervals prior to the LIA starts. Bottom: PDFs of $\Delta T$ within the LIA (blue) and in the previous 85 years (black). Dashed lines show the means of the distributions. While the two PDFs are statistically distinct for LIA1 and LIA2, LIA3 is not distinct from the previous 85 years within the uncertainties in the data. 